\title{
DMSO-Perturbing Assay for Identifying Promiscuous Enzyme Inhibitors
}

\author{
Keisuke Tomohara, ${ }^{*}{ }^{\dagger}$ Isao Adachi, ${ }^{\ddagger}$ Yoshikazu Horino, ${ }^{\S}$ Hitoshi Kesamaru, ${ }^{\#}$ Hitoshi Abe, ${ }^{\S}$ \\ Keitaro Suyama, ${ }^{\dagger}$ and Takeru Nose ${ }^{*}, *, \#$ \\ ${ }^{\dagger}$ Faculty of Arts and Science, Kyushu University, 744 Motooka, Nishi-ku, Fukuoka 819-0395, Japan \\ ${ }^{\ddagger}$ Department of Hospital Pharmacy, University of Toyama, 2630 Sugitani, Toyama 930-0194, Japan \\ ${ }^{\S}$ Graduate School of Science and Engineering, University of Toyama, 3190 Gofuku, Toyama 930-8555, Japan \\ ${ }^{\#}$ Graduate School of Science, Kyushu University, 744 Motooka, Nishi-ku, Fukuoka 819-0395, Japan
}

\section{Supporting Information}
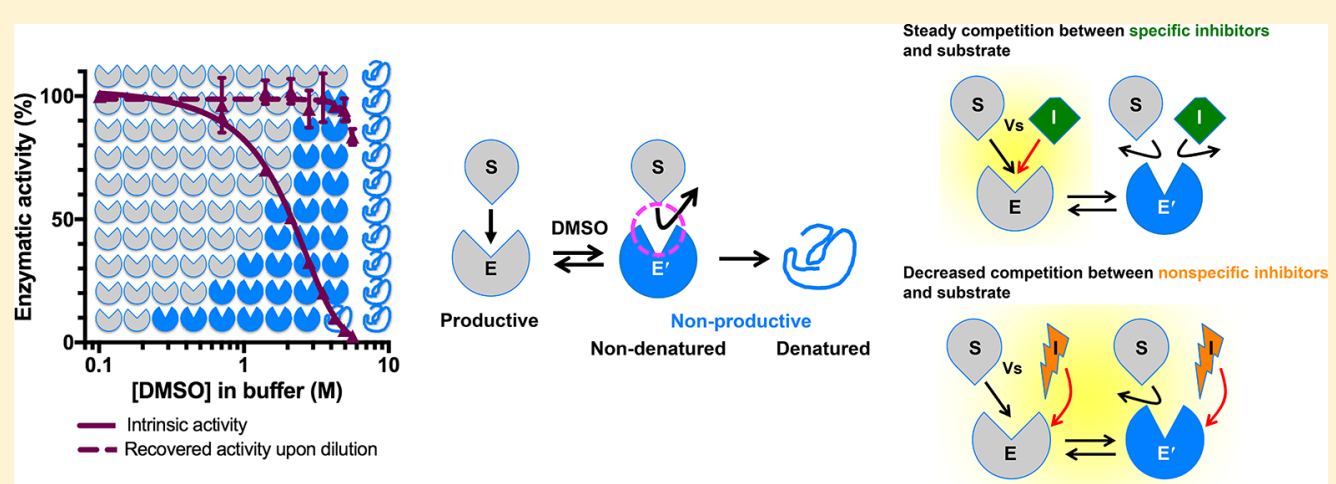

ABSTRACT: In search for enzyme inhibitors, we often encounter "promiscuous" enzyme inhibitors exhibiting nonspecific binding property toward enzyme active site. Therefore, inhibitory candidates should be mechanistically characterized as early as possible in discovery processes. However, there remains a lack of highly reliable and readily available methodology to evaluate specificity of initial hits inhibitors. The present study developed and established a novel DMSO-perturbing assay to identify promiscuous enzyme inhibitors. The assay successfully identified nonspecific binding inhibitors with a broad scope, typically by the attenuation of inhibitory activity by the influence of DMSO-addition. This attenuation would be attributed to the nonspecific binding property of inhibitors toward both productive and nonproductive (nondenatured) states of enzymes in perturbation solution. This working hypothesis was supported by spectroscopic analyses of enzyme conformations and analyses of solvent effects on perturbation. Overall, these results provided a novel concept of the DMSO-perturbing assay.

KEYWORDS: DMSO, perturbation, enzyme inhibitor, nonspecific binding

$\mathrm{D}$ iscovery and development of novel and well-behaved enzyme inhibitors have been, and will continue to be, challenging tasks. The success of the tasks depends heavily on the quality of the initial screening hits. If mechanistically poorly characterized initial hits are delivered for lead generation, subsequent evaluations will uncover their "promiscuous" activities because of lacking target specificity. ${ }^{1,2}$ Promiscuity has been gradually recognized by pharmaceutical communities, $^{3}$ prompting us to develop a method of identifying promiscuous molecules. Among the prevalent mechanistic descriptions of promiscuous enzyme inhibitors are covalent modification of enzymes, redox activity, and assay interference. These promiscuous molecules typically share common substructural motifs and thus have been referred to as pan-assay interference compounds (PAINS). ${ }^{4}$ Another wellrecognized mechanism for promiscuity is aggregation-based inhibition. $^{2}$ It has been proposed that, in assay buffer, micromolar and submicromolar concentrations of small chemicals form colloidal aggregates, then the aggregates hold enzymes on their surfaces, partially unfolding the native structure and diminishing the activity. ${ }^{5}$ Even with these understandings, however, many initial hit inhibitors still display undetected artificial inhibitory activities. Thus, there remains an urgent need to develop highly reliable and readily available methodology for identifying promiscuous enzyme inhibitors.

Dimethyl sulfoxide (DMSO) dissolves both hydrophobic and hydrophilic molecules and thus serves as a popular solvent for drug discovery study. In typical assays, DMSO is used at extremely low concentrations to ensure the intrinsic activity. At higher concentrations, DMSO perturbs the enzyme conforma-

Received: March 7, 2019

Accepted: May 10, 2019

Published: May 10, 2019 
Table 1. Enzyme Inhibitory Activity $\left(\mathrm{IC}_{50} \text { values, } \mu \mathrm{M}\right)^{a}$ of the Test Compounds

\begin{tabular}{|c|c|c|c|c|c|}
\hline \multirow[b]{2}{*}{ entry } & \multirow[b]{2}{*}{ compound } & \multicolumn{2}{|c|}{$\beta$-lactamase from Enterobacter cloacae } & \multicolumn{2}{|c|}{$\alpha$-Chymotrypsin } \\
\hline & & no detergent & with detergent ${ }^{b}$ & no detergent & with detergent ${ }^{b}$ \\
\hline 1 & quercetin & $85 \pm 2.1$ & $>500^{c}$ & $132 \pm 2.9$ & $130 \pm 3.8$ \\
\hline 2 & rutin & $>500(15 \pm 5.2)^{c}$ & $\mathrm{nt}^{d}$ & $296 \pm 5.2$ & $281 \pm 6.1$ \\
\hline 3 & phloretin & $496 \pm 25$ & $\mathrm{nd}^{e}$ & $>300(9.9 \pm 2.3)^{f}$ & $\mathrm{nt}^{d}$ \\
\hline 4 & rottlerin & $96 \pm 4.6$ & $142 \pm 20$ & $\mathrm{nd}^{g}$ & $\mathrm{nt}^{d}$ \\
\hline 5 & $3^{\prime}, 4^{\prime}$-dihydroxyflavone & $\mathrm{nd}^{g}$ & $\mathrm{nt}^{d}$ & $226 \pm 8.7$ & $270 \pm 9.2$ \\
\hline 6 & potassium clavulanate & $539 \pm 22$ & $330 \pm 15$ & & \\
\hline 7 & penicillin $\mathrm{G}$ & $7.2 \pm 0.29$ & $3.6 \pm 0.072$ & & \\
\hline 8 & chymostatin & & & $7.2 \pm 0.23$ & $6.7 \pm 0.33$ \\
\hline
\end{tabular}

tions, causing a gradual and reversible decrease in catalytic activities. Such structural and catalytic perturbations of enzymes by DMSO have been utilized for mechanistic investigations of enzyme structure, folding/unfolding process, reactivity, and binding affinity of ligand. We have previously applied such DMSO-induced perturbation conditions to an inhibitory assay of hyaluronidase (HA) and described the DMSO-perturbed behaviors of nonspecific binding HA inhibitors for the first time. ${ }^{6}$ Here, we applied the DMSOperturbing methodology to the inhibitory assay of two $\beta$ lactamases and $\alpha$-chymotrypsin. The use of these wellcharacterized enzymes would advance the fundamental understandings about the scope, practicality, and mechanisms of the DMSO-perturbing assay.

The present study began with inhibitory screenings of 18 structurally diverse compounds, including naturally occurring frequent hitters, ${ }^{7}$ their structural relatives, and molecules identified as nonspecific binding HA inhibitors in our previous studies (Figure S1), ${ }^{6,8}$ toward $\beta$-lactamase from Enterobacter cloacae (BL), $\beta$-lactamase from Bacillus cereus 569/H9 (results are provided in Supporting Information), and bovine pancreatic $\alpha$-chymotrypsin (CT). First, a set of test compounds was subjected to typical enzyme inhibitory assay ${ }^{9}$ to pick up the initial hit inhibitors. Among them, only quercetin, ${ }^{7}$ a well-known frequent hitter, exhibited multiple potent inhibitory activities toward $\mathrm{BL}$ and $\mathrm{CT}$ with $\mathrm{IC}_{50}$ values of 85 and $132 \mu \mathrm{M}$, respectively, although it was structurally unlike their substrates (Table 1, entry 1). Rutin inhibited CT with an $\mathrm{IC}_{50}$ value of $296 \mu \mathrm{M}$; however, it did not show inhibitory activity toward BL (entry 2). Flavonoids, such as phloretin and rottlerin, inhibited $\mathrm{BL}$ with moderate to high inhibitory activity $\left(\mathrm{IC}_{50}=496\right.$ and $96 \mu \mathrm{M}$, respectively), while $3^{\prime}, 4^{\prime}$-dihydroxyflavone inhibited CT with an $\mathrm{IC}_{50}$ value of 226 $\mu \mathrm{M}$ (entries 3-5). Other frequent hitters such as (-)-epicatechin, (-)-epigallocatechin-3-gallate, baicalin, and glycyrrhizin were consistently inactive toward these enzymes (Tables S1 and S2). Notably, molecules having the same substructures did not always exhibit similar inhibitory behaviors. Indeed, frequent hitters often do not behave as promiscuous molecules. ${ }^{10-12}$ Additionally, sodium cromoglicate, indomethacin, and L-ascorbyl palmitate did not exhibit inhibitory activities toward CT and the BLs even though they have been previously identified as nonspecific binding inhibitors of HA (Tables S1 and S2). These results indicated that structural appearance and single assay evaluation do not always provide satisfactory insight into the target specificity of enzyme inhibitors and that initial hits should undergo careful mechanistic characterizations through a set of orthogonal assays, molecule-by-molecule. ${ }^{10}$ Positive controls, penicillin G and potassium clavulanate, inhibited $\mathrm{BL}$ with moderate to high potency $\left(\mathrm{IC}_{50}=539\right.$ and $7.2 \mu \mathrm{M}$, respectively) (entries 6 and 7). These inhibitory tendencies agreed well with previous measurements. ${ }^{13}$ Similarly, chymostatin, a well-known competitive inhibitor of CT, inhibited CT with an $\mathrm{IC}_{50}$ value of 7.2 $\mu \mathrm{M}$, in line with the reported value (entry 8$).^{9 \mathrm{~b}}$

With the initial hits in hand, we then examined the possibility of promiscuous aggregation-based inhibition according to the well-established Shoichet's protocol (detergent-addition assay). ${ }^{14}$ Mechanistically, adding a detergent into assay mixture saturates or disrupts the aggregates, thereby attenuating the inhibitory activity. The analysis was performed by adding a nonionic detergent Triton X-100 (TX-100) at a final concentration of $0.05 \%(\mathrm{v} / \mathrm{v})$ (Table 1$)$. The results of this assay were not straightforward. The inhibitory activity of quercetin toward BL was greatly attenuated upon adding TX100 , although its inhibitory activity toward CT was unaffected by TX-100 (entry 1). 3,4-Dihydroxyflavone also showed the decreased inhibitory activity with TX-100 (entry 5). Thus, quercetin (for BL) and 3,4-dihydroxyflavone were clearly concluded as aggregating inhibitors. The inhibitory activity of rottlerin toward $\mathrm{BL}$ was attenuated by $\mathrm{TX}-100$, and it was thus flagged as a potential aggregator (entry 4). However, because the behaviors of the concentration-response curves were quite variable between runs (Figure S2), this assignment was inconclusive. Phloretin was unsuitable for this assay because it precipitated even at a low TX-100 concentration $(0.01 \%, \mathrm{v} /$ v) (entry 3 ). The inhibitory activity of rutin slightly increased with TX-100, rendering its mode of inhibition uncertain (entry 2). Among positive controls, chymostatin did not show any significant change in the $\mathrm{IC}_{50}$ value with $\mathrm{TX}-100$ as expected (entry 8), while the inhibitory activities of potassium clavulanate and penicillin $G$ significantly increased by adding TX-100 (entries 6 and 7). These results indicated some difficulties and ambiguities of this analysis as previously reported. ${ }^{5,15,16}$

Subsequently, the mechanistic characterization of inhibitors was performed by our DMSO-perturbing assay. First, the intrinsic catalytic activities of the BLs and CT were measured at different DMSO/buffer concentrations (Figures 1 and S3). Their activities gradually decreased as DMSO concentration increased, and the attenuated activities turned out to be almost fully recoverable upon incubating the enzymes at different DMSO concentrations and then transferring them to DMSOfree working solutions (dilution test). ${ }^{17}$ These results indicated 


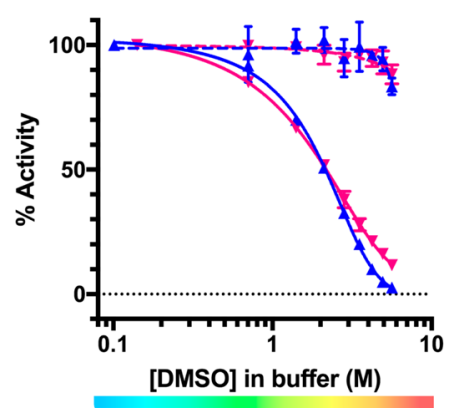

Figure 1. Solid lines indicate the intrinsic catalytic activities of the BL $(\boldsymbol{\Delta})$ and CT $(\boldsymbol{\nabla})$ at different DMSO concentrations. Broken lines indicate the recovered activities upon 10-fold dilutions. Data are presented as the mean \pm SD from at least three independent experiments.

that DMSO deactivated the enzymes in a reversible manner under the following DMSO-perturbing assay conditions (up to $\sim 2$ M DMSO).

Then, the inhibitory behaviors of $\mathrm{BL}$ inhibitors were evaluated under the modified assay conditions by adding extra DMSO, whose concentration was increased stepwise from 0.7 to $2.1 \mathrm{M}$ (final concentration). Experimentally, enzymes were preincubated in a DMSO-containing assay solution before adding inhibitors. As a result, the concentration-response curves of $\beta$-lactams, penicillin $\mathrm{G}$ and potassium clavulanate, remained unaffected by adding DMSO (Figures $2 \mathrm{~A}, \mathrm{~B}$ and S4), while those of non- $\beta$-lactams,
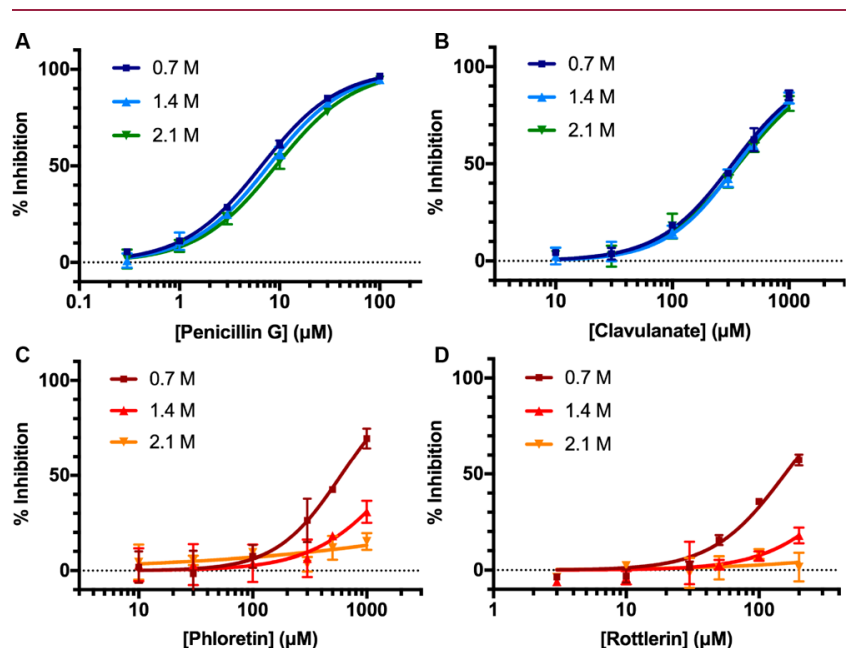

Figure 2. Concentration-response curves of penicillin G (A), potassium clavulanate (B), phloretin (C), and rottlerin (D) in the DMSO-perturbing assay. The legends in each panel indicate a final concentration of DMSO. Data are presented as the mean \pm SD from at least three independent experiments.

phloretin and rottlerin, were right-shifted with increasing DMSO concentrations, indicating a statistically significant attenuation of their inhibitory activities (Figure 2C,D). These inhibitory tendencies of $\beta$-lactams and non- $\beta$-lactams toward $\mathrm{BL}$ in the DMSO-perturbing assay matched well with those of polysaccharide and nonpolysaccharide HA inhibitors. ${ }^{6}$

For the comparable study with $\mathrm{CT}$, the assay was performed using $N$-succinyl-L-phenylalanine-p-nitroanilide as a substrate in the presence of $6 \mu \mathrm{M} \mathrm{CT}$. As a result, a peptidic chymostatin showed almost steady inhibitory activity in the presence of
DMSO, indicating a catalytic site-specific binding mode of inhibition, although a slight decrease in inhibitory activity was observed (Figure 3A). This decrease may be due to nonspecific

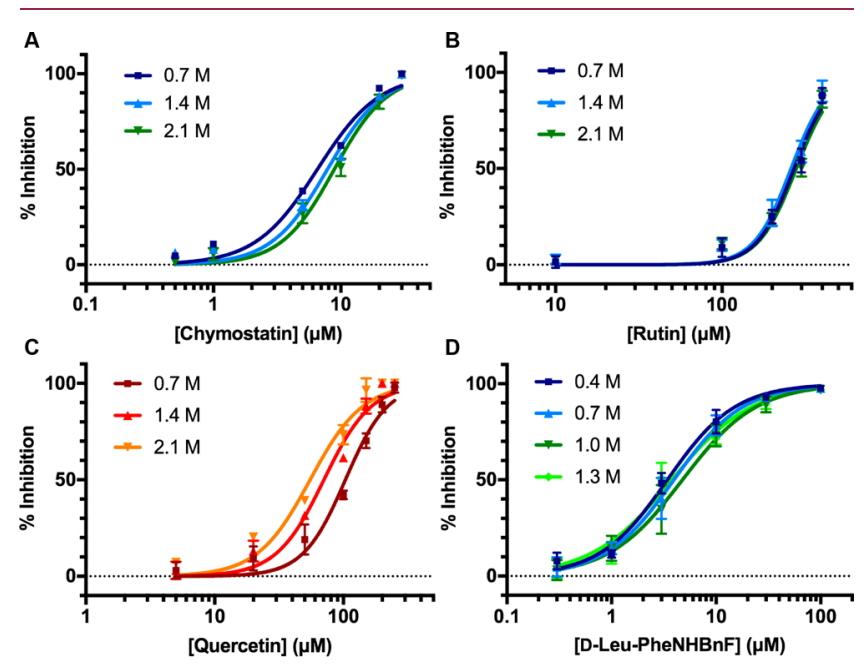

Figure 3. Concentration-response curves of chymostatin (A), rutin (B), quercetin (C), and D-Leu-PheNHBnF (D) in the DMSOperturbing assay. The legends in each panel indicate a final concentration of DMSO. Data are presented as the mean \pm SD from at least three independent experiments.

covalent bond formation between the electrophilic aldehyde group of chymostatin and nucleophilic residues in CT. ${ }^{18}$ Rutin, although structurally unlike the substrate, also showed steady inhibitory activity under the DMSO-perturbing conditions (Figure 3B). Although this behavior matched a specific inhibition pattern, there remained the possibility of allosteric inhibition as described previously. ${ }^{8}$ However, the inhibitory activity of quercetin increased as DMSO concentration increased (Figure 3C). Our previously discovered CT inhibitor, D-leucyl-L-phenylalanyl $p$-fluorobenzylamide (D-LeuPheNHBnF) (Figure S1), ${ }^{19}$ whose catalytic site-specificity has been elucidated by a combination of kinetic, ${ }^{1} \mathrm{H}$ NMR conformational, and X-ray crystallographic studies, ${ }^{20,21}$ also exhibited steady inhibitory activity in the presence of DMSO (Figure 3D). Notably, these inhibitory behaviors in the DMSO-perturbation assay were also observed at 1000-times lower concentration of CT $(6 \mathrm{nM})$ using $N$-succinyl-L-alanineL-alanine-L-proline-L-phenylalanine-p-nitroanilide as a substrate with high detection sensitivity, although those inhibitors showed stronger inhibitory effects (Figure S5). Therefore, it was found that the DMSO-perturbing assay could be available regardless of enzyme concentration and potency of inhibitors.

Although these nonspecific binding inhibitors (quercetin, rottlerin, and phloretin) did not show any detectable levels of aggregating properties by the aforementioned detergentaddition test, DMSO may have perturbed the particle form of inhibitors and thereby increased or decreased inhibitory activity. Therefore, we evaluated their particle size distributions at different $\mathrm{DMSO} /$ buffer concentrations through dynamic light scattering (DLS) analysis. As a result, the intensityweighted size distributions of these inhibitors remained unchanged regardless of the DMSO concentrations (Figure S6). Thus, it was confirmed that the DMSO-perturbed inhibitory behaviors seemed unrelated to their particle forms in the DMSO/buffer solution. Then, the structural stability of these inhibitors during the assay was evaluated by the quality 
control analysis; after incubation, the inhibitors were extracted from incubation mixtures and subjected to ${ }^{1} \mathrm{H}$ NMR analysis (Figure S7). As a result, quercetin and rottlerin were recovered with small amounts of byproducts, and therefore, the possibility of nonspecific inhibition through redox cycling has to be questioned. Thus, their inhibitory activities were evaluated in the presence of $1 \mathrm{mM}$ reductant dithiothreitol (DTT). ${ }^{22}$ As expected, quercetin showed the decreased IC $_{50}$ value $(224 \pm 1.8 \mu \mathrm{M})$ by DTT (vs Table 1 , entry 1 ) such that quercetin was considered to exhibit redox reactivity in the present assay. Thus, the increased inhibitory activity of quercetin by adding DMSO might be due to the enhanced redox reactivity. ${ }^{23}$ Similarly, the inhibitory potency of rottlerin for $\mathrm{BL}$ became less than $50 \%$ inhibition even at $200 \mu \mathrm{M}$ by DTT (vs Table 1, entry 4). The decreased inhibitory activity of rottlerin by adding DTT might be attributable to the inherent reactivity of its conjugated ketone moiety, which enables nonspecific covalent bond formation toward enzymes. It should be noted that, throughout these mechanistic considerations, the behavior of phloretin was completely unchanged. Thus, our perturbation assay could advantageously highlight such a simple nonspecific binding mode of inhibition, which is rarely highlighted by conventional methods.

The working hypothesis of the DMSO-perturbed assay is as follows. In usual assays, DMSO is used at extremely low concentrations, and almost all enzymes are present in a native (productive) state and exhibit the intrinsic activity; productive enzymes (E) reversibly bind to substrates (S) to form enzyme-substrate (ES) complexes, which then undergo a catalytic reaction to yield designated products $(\mathrm{P})$. In the DMSO-perturbing assay, enzymes are preincubated with DMSO, which induces structural and catalytic perturbations of enzymes. Under such perturbation conditions, the overall enzymes could be divided into two populations in terms of the catalytic site availability: one is an assembly of productive enzymes (E) and the other is an assembly of nonproductive but nondenatured enzymes $\left(E^{\prime}\right)$ (Figure 4). Here, $E^{\prime}$ is defined
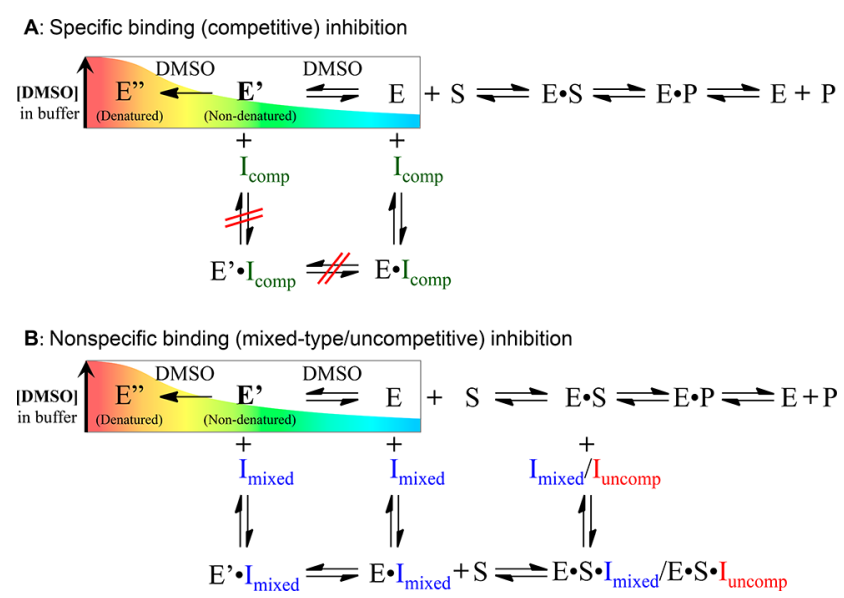

Figure 4. Schematic drawings of specific binding inhibition (A) and nonspecific binding inhibition (B) in the DMSO-perturbing assay.

as an enzyme having global structural nativeness but having no catalytic activity, in contrast to a denatured enzyme ( $\left.E^{\prime \prime}\right)$ whose catalytic activity and native conformation are irreversibly lost. This assumption would be reasonable considering that conformational perturbation around catalytic residues exerts fatal effects on the catalytic activity. Here, catalytic site- specific inhibitors $\left(\mathrm{I}_{\text {comp }}\right)$ interact exclusively with $\mathrm{E}$, competing with $S$, and thus retaining the intrinsic inhibitory potencies (Figure 4A), although the apparent enzymatic activity reduced as DMSO concentration increased. $\beta$-Lactam $\mathrm{BL}$ inhibitors (penicillin G and clavulanate) and a peptidic CT inhibitor (chymostatin) would be classified into this type of inhibition. However, nonspecific binding inhibitors $\left(\mathrm{I}_{\text {mixed }}\right)$ bind not only to E and ES complexes but also to $\mathrm{E}^{\prime}$; as the latter interactions do not compete with $S$, and thus, the inhibitory activity is attenuated (Figure 4B). This type of inhibition was observed in the cases of non- $\beta$-lactam $\mathrm{BL}$ inhibitors (phloretin and rottlerin). If the inhibitor only binds to the ES complex, the inhibitory activity would be increased in the presence of DMSO due to the relatively decreased concentration of ES complexes compared to the steady concentration of inhibitor. Thus, the decreased or increased inhibitory activity of inhibitors by adding DMSO would indicate the nonspecific binding attributes. Compared with classical kinetic analysis, the DMSO-perturbing assay offers the following advantages: the assay can be operated under simply modified assay conditions by adding extra DMSO. Therefore, our methodology would be applicable to a variety of assay systems. Furthermore, there is no need for pseudo-secondorder reaction conditions and/or undesired double reciprocal plot analyses often used in kinetic analyses. Remarkably, the weaker inhibitory potency the inhibitors have, the more clearly the DMSO-perturbing assay identifies their nonspecific binding properties.

To get insights into the DMSO-induced structural changes of enzymes, fluorescence spectra derived from tryptophan residues of enzymes were recorded at different DMSO/buffer concentrations (Figures 5A). At an emission wavelength of 295

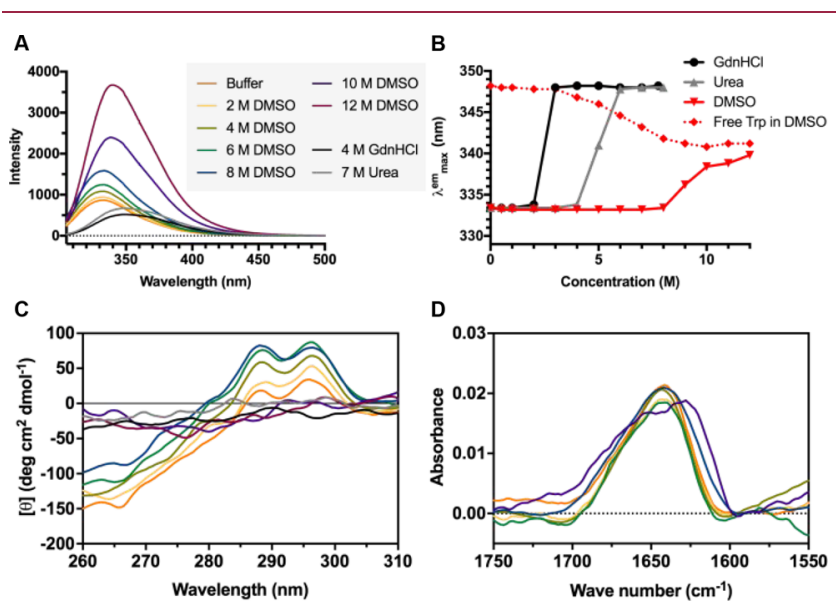

Figure 5. Emission spectra of CT (A) and $\lambda^{\mathrm{em}}{ }_{\text {max }}$ (B) with $295 \mathrm{~nm}$ excitation, near-UV CD spectra of CT (C), and IR spectra of deuterated CT (D), at different concentrations of DMSO, $\mathrm{GdnHCl}$, and urea.

$\mathrm{nm}$, the intrinsic maximum emission wavelength $\left(\lambda^{\mathrm{em}}{ }_{\max }\right)$ of native CT appeared at $333 \mathrm{~nm}$ (Figure 5B). Under denaturation conditions with guanidine hydrochloride $(\mathrm{GdnHCl})$ and urea, however, the $\lambda_{\text {max }}^{\mathrm{em}}$ was red-shifted to $348 \mathrm{~nm}$, which corresponds to the specific emission wavelength of free tryptophan, indicating that the tryptophan residues originally buried in the hydrophobic cores of CT became exposed to a polar environment and that CT was assumed to be unfolded. ${ }^{24}$ When $\mathrm{CT}$ was treated with different 
DMSO concentrations, the $\lambda^{\mathrm{em}}{ }_{\max }$ remained unchanged up to 8 $M$ concentration, although the UV absorption increased monotonically upon DMSO-addition because of solvent effects. $^{25}$ The similar behaviors were also observed for the BLs (Figure S8). Then, circular dichroism (CD) spectra of CT were measured at different DMSO/buffer concentrations. To preclude the intrinsic UV absorption of DMSO, the measurements were performed in the near-UV region. As described previously, ${ }^{26}$ native CT afforded characteristic positive bands at 285 and $300 \mathrm{~nm}$, which were attributable to tyrosine and tryptophan residues, respectively (Figure 5C), and those were observed up to $8 \mathrm{M}$ DMSO concentration. Then, these characteristic bands completely disappeared, and the spectra resembled those with $\mathrm{GdnHCl}(4 \mathrm{M})$ and urea $(7 \mathrm{M})$. Furthermore, the conformational changes in the peptide backbone were examined by measuring the IR spectra of deuterated CT (Figure 5D). In the deuterated buffer, the characteristic absorptions of amide I appeared at $1640 \mathrm{~cm}^{-1}$, and this absorption was observed up to $8 \mathrm{M}$ DMSO concentration. Then, the maximum absorption shifted to around $1620 \mathrm{~cm}^{-1}$; this behavior agreed with that previously reported for 2,2,2-trifluoroethanol (TFE)-induced non-nativeness of $\mathrm{CT}^{27}$ Overall, these spectral analyses implied that there were no structural changes around the tyrosine and tryptophan residues and the peptide backbone of CT at the DMSO concentrations required for the assay (up to $\sim 2 \mathrm{M}$ ), thereby suggesting that the decreased enzymatic activity by adding DMSO would be due to the existence of nonproductive (nondenatured) enzyme state. This consideration is also supported by the well-known bilateral properties of DMSO on CT: within the concentration range of 0 to $50 \%(\mathrm{v} / \mathrm{v})$, DMSO stabilizes the global conformation of CT and destabilizes the local conformation especially within and around the active site. ${ }^{28}$

Finally, to examine the solvent effects on perturbation the enzymatic activity of BL was evaluated in the presence of water-compatible additives including ethanol, TFE, acetone, $\mathrm{N}, \mathrm{N}$-dimethylacetamide (DMA), urea, and $\mathrm{GdnHCl}$ (Figure S9). Among them, the addition of DMA could afford DMSOlike perturbation conditions (Figure S9D), wherein BL inhibitors, $\beta$-lactam penicillin $\mathrm{G}$ and non- $\beta$-lactam phloretin, behaved as in DMSO-perturbation assay (Figure S10A,B). Conversely, the addition of $\mathrm{GdnHCl}$ caused a gradual decrease in the catalytic activity at quite low concentration, and the diminished activity was poorly recovered after dilution (Figure S9F). This irreversibility implied that the addition of $\mathrm{GdnHCl}$ would generate a nonproductive denatured enzyme. Once denatured, it would no longer interact with substrate as well as both specific and nonspecific binding inhibitors. Both inhibitors, in turn, interact only with productive enzyme, wherein competing with substrate and retaining the intrinsic inhibitory activity. This assumption was supported by the observation that the inhibitory activities of penicillin $G$ and phloretin remained unaffected by adding $\mathrm{GdnHCl}$ (Figure S10C,D). These contrasting results observed by adding DMA and $\mathrm{GdnHCl}$ supported our working hypothesis: the DMSOperturbed inhibitory behaviors of nonspecific binding inhibitors were attributed to the existence of nonproductive (nondenatured) states of enzymes in assay solutions.

In summary, this study examined and established a novel DMSO-perturbing assay to identify promiscuous enzyme inhibitors. The assay successfully identified several nonspecific binding enzyme inhibitors with a broad scope, typically by the attenuation of inhibitory activity in a manner dependent on DMSO concentration. The attenuated inhibitory activities were attributed to the nonspecific binding properties of inhibitors toward both productive and nonproductive (nondenatured) enzyme states. The existence of key nonproductive (nondenatured) enzymes during the assay was verified by spectroscopic analyses. Consequently, this study provided a readily available and robust method to evaluate the target specificity of initial hits, which can be effectively used in the early stages of drug discovery.

\section{ASSOCIATED CONTENT}

\section{S Supporting Information}

The Supporting Information is available free of charge on the ACS Publications website at DOI: 10.1021/acsmedchemlett.9b00093.

Experimental procedures, supporting tables and figures (PDF)

\section{AUTHOR INFORMATION}

\section{Corresponding Authors}

*Phone: (+81) 92-802-5784. E-mail: tomohara@artsci.kyushuu.ac.jp (K.T.).

*Phone: (+81) 92-802-6025. E-mail: nose@artsci.kyushu-u.ac. jp (T.N.).

ORCID $\odot$

Keisuke Tomohara: 0000-0003-2305-5963

Yoshikazu Horino: 0000-0002-8916-6298

Takeru Nose: 0000-0001-9771-7267

Funding

This work was supported by the JSPS KAKENHI Grant Numbers JP26870217 and JP17K17750, Tamura Science and Technology Foundation, and Kanamori Foundation.

Notes

The authors declare no competing financial interest.

\section{ACKNOWLEDGMENTS}

The authors acknowledged Dr. A. Matsushima (Kyushu University) for CD measurement, Dr. T. Uchida (Kyushu University) for IR measurement, and Dr. T. Mori and Mr. Y. Liu (Kyushu University) for DLS measurement. DLS measurement was supported by Nanotechnology Platform Program (Molecule and Material Synthesis) of the Ministry of Education, Culture, Sports, Science and Technology (MEXT), Japan.

\section{ABBREVIATIONS}

DMSO, dimethyl sulfoxide; HA, hyaluronidase; BL, $\beta$ lactamase from E. cloacae; CT, $\alpha$-chymotrypsin; TX-100, Triton X-100; DTT, dithiothreitol; CD, circular dichroism; $\mathrm{GdnHCl}$, guanidine hydrochloride; TFE, 2,2,2-trifluoroethanol; DMA, N,N-dimethylacetamide

\section{REFERENCES}

(1) Roche, O.; Schneider, P.; Zuegge, J.; Guba, W.; Kansy, M.; Alanine, A.; Bleicher, K.; Danel, F.; Gutknecht, E.-M.; Rogers-Evans, M.; Neidhart, W.; Stalder, H.; Dillon, M.; Sjögren, E.; Fotouhi, N.; Gillespie, P.; Goodnow, R.; Harris, W.; Jones, P.; Taniguchi, M.; Tsujii, S.; von der Saal, W.; Zimmermann, G.; Schneider, G. Development of a Virtual Screening Method for Identification of "Frequent Hitters" in Compound Libraries. J. Med. Chem. 2002, 45, 137-142. 
(2) McGovern, S. L.; Caselli, E.; Grigorieff, N.; Shoichet, B. K. A Common Mechanism Underlying Promiscuous Inhibitors from Virtual and High-Throughput Screening. J. Med. Chem. 2002, 45, $1712-1722$.

(3) Aldrich, C.; Bertozzi, C.; Georg, G. I.; Kiessling, L.; Lindsley, C.; Liotta, D.; Merz, K. M., Jr.; Schepartz, A.; Wang, S. The Ecstasy and Agony of Assay Interference Compounds. ACS Med. Chem. Lett. 2017, $8,379-382$.

(4) Baell, J. B.; Nissink, J. W. M. Seven Year Itch: Pan-Assay Interference Compounds (PAINS) in 2017-Utility and Limitations. ACS Chem. Biol. 2018, 13, 36-44.

(5) Coan, K. E. D.; Shoichet, B. K. Stoichiometry and Physical Chemistry of Promiscuous Aggregate-Based Inhibitors. J. Am. Chem. Soc. 2008, 130, 9606-9612.

(6) Tomohara, K.; Ito, T.; Onikata, S.; Furusawa, K.; Kato, A.; Adachi, I. Interpreting the behavior of concentration-response curves of hyaluronidase inhibitors under DMSO-perturbed assay conditions. Bioorg. Med. Chem. Lett. 2016, 26, 3153-3157.

(7) Bisson, J.; McAlpine, J. B.; Friesen, J. B.; Chen, S.-N.; Graham, J.; Pauli, G. F. Can Invalid Bioactives Undermine Natural Product-Based Drug Discovery? J. Med. Chem. 2016, 59, 1671-1690.

(8) Tomohara, K.; Ito, T.; Onikata, S.; Kato, A.; Adachi, I. Discovery of hyaluronidase inhibitors from natural products and their mechanistic characterization under DMSO-perturbed assay conditions. Bioorg. Med. Chem. Lett. 2017, 27, 1620-1623.

(9) For $\beta$-lactamase: (a) Conrath, K. E.; Lauwereys, M.; Galleni, M.; Matagne, A.; Frere, J.-M.; Kinne, J.; Wyns, L.; Muyldermans, S. $\beta$ Lactamase Inhibitors Derived from Single-Domain Antibody Fragments Elicited in the Camelidae. Antimicrob. Agents Chemother. 2001, 45, 2807-2812. For $\alpha$-chymotrypsin: (b) Uddin, N.; Siddiqui, B. S.; Begum, S.; Ali, M. I.; Marasini, B. P.; Khan, A.; Choudhary, M. I. Bioassay-guided isolation of urease and $\alpha$-chymotrypsin inhibitory constituents from the stems of Lawsonia alba Lam. (Henna). Fitoterapia 2013, 84, 202-207.

(10) Capuzzi, S. J.; Muratov, E. N.; Tropsha, A. Phantom PAINS: Problems with the Utility of Alerts for Pan-Assay INterference CompoundS. J. Chem. Inf. Model. 2017, 57, 417-427.

(11) Gilberg, E.; Stumpfe, D.; Bajorath, J. Activity profiles of analog series containing pan assay interference compounds. RSC Adv. 2017, 7, 35638-35647.

(12) Jasial, S.; Hu, Y.; Bajorath, J. How Frequently Are Pan-Assay Interference Compounds Active? Large-Scale Analysis of Screening Data Reveals Diverse Activity Profiles, Low Global Hit Frequency, and Many Consistently Inactive Compounds. J. Med. Chem. 2017, 60, 3879-3886.

(13) Coleman, K. Diazabicyclooctanes (DBOs): a potent new class of non- $\beta$-lactam $\beta$-lactamase inhibitors. Curr. Opin. Microbiol. 2011, $14,550-555$.

(14) Feng, B. Y.; Shoichet, B. K. A detergent-based assay for the detection of promiscuous inhibitors. Nat. Protoc. 2006, 1, 550-553.

(15) Jadhav, A.; Ferreira, R. S.; Klumpp, C.; Mott, B. T.; Austin, C. P.; Inglese, J.; Thomas, C. J.; Maloney, D. J.; Shoichet, B. K.; Simeonov, A. Quantitative Analyses of Aggregation, Autofluorescence, and Reactivity Artifacts in a Screen for Inhibitors of a Thiol Protease. J. Med. Chem. 2010, 53, 37-51.

(16) Pohjala, L.; Tammela, P. Aggregating Behavior of Phenolic Compounds - A Source of False Bioassay Results? Molecules 2012, 17, 10774-10790.

(17) Copeland, R. A. Evaluation of Enzyme Inhibitors in Drug Discovery: A Guide for Medicinal Chemists and Pharmacologists; John Wiley \& Sons Inc: Hoboken, 2005; pp 125-128.

(18) Tomkinson, N. P.; Galpin, I. J.; Beynon, R. J. Synthetic analogues of chymostatin. Inhibition of chymotrypsin and Streptomyces griseus proteinase A. Biochem. J. 1992, 286, 475-480.

(19) Shimohigashi, Y.; Maeda, I.; Nose, T.; Ikesue, K.; Sakamoto, H.; Ogawa, T.; Ide, Y.; Kawahara, M.; Nezu, T.; Terada, Y.; Kawano, K.; Ohno, M. Chymotrypsin inhibitory conformation induced by amino acid side chain-side chain intramolecular $\mathrm{CH} / \pi$ interaction. J. Chem. Soc., Perkin Trans. 1 1996, 2479-2485.
(20) Kashima, A.; Inoue, Y.; Sugio, S.; Maeda, I.; Nose, T.; Shimohigashi, Y. X-ray crystal structure of a dipeptide-chymotrypsin complex in an inhibitory interaction. Eur. J. Biochem. 1998, 255, 1223.

(21) Shimohigashi, Y.; Nose, T.; Yamauchi, Y.; Maeda, I. Design of Serine Protease Inhibitors with Conformation Restricted by Amino Acid Side-Chain-Side-Chain $\mathrm{CH} / \pi$ Interaction. Biopolymers 1999, 51, 9-17.

(22) Dahlin, J. L.; Nissink, J. W. M.; Strasser, J. M.; Francis, S.; Higgins, L.; Zhou, H.; Zhang, Z.; Walters, M. A. PAINS in the Assay: Chemical Mechanisms of Assay Interference and Promiscuous Enzymatic Inhibition Observed during a Sulfhydryl-Scavenging HTS. J. Med. Chem. 2015, 58, 2091-2113.

(23) Bors, W.; Michel, C.; Schikora, S. Interaction of flavonoids with ascorbate and determination of their univalent redox potentials: A pulse radiolysis study. Free Radical Biol. Med. 1995, 19, 45-52.

(24) Falcone, R. D.; Biasutti, M. A.; Correa, N. M.; Silber, J. J.; Lissi, E.; Abuin, E. Effect of the Addition of a Nonaqueous Polar Solvent (Glycerol) on Enzymatic Catalysis in Reverse Micelles. Hydrolysis of 2-Naphthyl Acetate by $\alpha$-Chymotrypsin. Langmuir 2004, 20, 57325737.

(25) Fink, A. L. The $\alpha$-Chymotrypsin-Catalyzed Hydrolysis of NAcetyl-L-tryptophan p-Nitrophenyl Ester in Dimethyl Sulfoxide at Subzero Temperatures. Biochemistry 1973, 12, 1736-1742.

(26) Wu, J.; Yang, J. T.; Wu, C.-S. C. $\beta$-II Conformation of All- $\beta$ Proteins Can Be Distinguished from Unordered Form by Circular Dichroism. Anal. Biochem. 1992, 200, 359-364.

(27) Dong, A.; Matsuura, J.; Manning, M. C.; Carpenter, J. F. Intermolecular $\beta$-Sheet Results from Trifluoroethanol-Induced Nonnative $\alpha$-Helical Structure in $\beta$-Sheet Predominant Proteins: Infrared and Circular Dichroism Spectroscopic Study. Arch. Biochem. Biophys. 1998, 355, 275-281.

(28) Tretyakova, T.; Shushanyan, M.; Partskhaladze, T.; Makharadze, M.; Eldik, R.; Khoshtariya, D. E. Simplicity within the complexity: Bilateral impact of DMSO on the functional and unfolding patterns of $\alpha$-chymotrypsin. Biophys. Chem. 2013, 175$176,17-27$. 